\title{
Fantasmas na teoria urbana contemporânea? Notas para reivindicar uma atitude crítica
}

\author{
Ghosts in contemporary urban theory? \\ Notes to claim a critical attitude
}

\section{Cristhian Parrado Rodríguez e Andrea Cevallos Aráuz}

\begin{abstract}
Resumo Este artigo propõe discutir o modelo de análise da teoria urbana contemporânea e o papel que joga o urbano e o descolonial nessa análise. Inicialmente, trata-se de explicar como a ideia tradicional de cidade - entendida como categoria analítica - e a colonialidade do saber - já que gera saberes hegemônicos e marginais - são os fantasmas que recorrem a teoria urbana na atualidade. A partir da reflexão sobre as perspectivas teóricas que ressaltam o "direito à cidade" e a descolonização do saber, o artigo conclui destacando o papel crucial que desempenha na teoria urbana crítica o conceito de cidade e as teorias do Norte global, mas não seus fantasmas.
\end{abstract}

Palavras-chave Direito à cidade; Descolonização do saber; Teoria urbana crítica.

Abstract This article proposes to discuss the analysis model of contemporary urban theory and the role played by the urban and the decolonial in it. Initially, he tries to explain how the traditional idea of the city - understood as an analytical category - and the coloniality of knowledge - since it generates hegemonic and marginal knowledge - are the ghosts that run through urban theory today. From reflecting on the theoretical perspectives that highlight the right to the city and the decolonization of knowledge, he concludes by highlighting the crucial role that the concept of city and the theories of the global North play in critical urban theory, but not its ghosts. Keywords Critical urban theory; Decolonization of knowledge; Right to the city.

\section{INTRODUÇÃO}

Marx e Engels (1971 [1848]) inauguraram o que seria um dos textos com maior influência no pensamento crítico e na ação política com as seguintes palavras: um fantasma ronda a Europa. Com esta frase faziam menção, por um lado, ao desenvolvimento das ideias comunistas a meados do século XIX e, por outro

a Mestrando em Estudos Urbanos (2016-2018) da FLACSO - Equador. Antropólogo especialista em Mercados e Políticas do Solo na América Latina pela Universidad Nacional de Colombia. Email: crgiparradofl@flacso.edu.ec.

b Mestranda em Estudos Urbanos (2016-2018) da FLACSO - Equador. Arquiteta da Universidad Central del Equador. Email: azuliverde7@gmail.com 
lado, a potencial ameaça que representavam para a destruição do capitalismo europeu e do mundo inteiro. Na atualidade, se questiona a validade desta profecia apocalíptica e se propõe falar da existência de outro fantasma: este não seria o comunismo senão, pior, o capitalismo neoliberal que, segundo Rodríguez (2013), é o fantasma da exploração. Desta maneira, a teoria traduziu esta metáfora - que destacava aspectos positivos para a transformação - em algo avassalador: com ela agora se pretende revelar como o capitalismo se dispersa de forma acelerada em todo o mundo e de maneira irreflexiva por nossas mentes.

No campo da teoria urbana, qual seria o fantasma? Ou, melhor dizendo, tem a teoria urbana algum fantasma que a recorra? Wachsmuth (2014) responde que sim. E tanto para ele, como para os representantes da chamada teoria urbana crítica, não é um fantasma positivo. No contexto da urbanização planetária (BRENNER, 2013) ou do universalismo urbano (WACHSMUTH, 2014), a ideia tradicional de cidade, com todo seu procedimento teórico e metodológico, se propaga como espectro: "um fantasma invisível, mas influente" (WACHSмuTH, 2014, p. 24; em livre tradução). Com esta metáfora, os teóricos urbanos críticos sugerem que a teoria urbana contemporânea está inserida em uma encruzilhada, onde visões analíticas do lugar persistem sobre os enfoques mais processuais do urbano. E isto se da a partir de processos teóricos irrefletidos que seguem assumindo a ideia tradicional de cidade como marco explicativo da urbanização capitalista contemporânea.

Não obstante, como se insinua mais à frente, é necessário complementar esta discussão desde a perspectiva da modernidade e a colonialidade considerada por vários autores (FArrés; Matarán, 2014; QuiJano, 2011; De SouZA SANTos, 2010; GrosFOGUEL 2007). Assume-se esta posição para identificar como os discursos globais da teoria urbana produzem outro fantasma: uma hierarquia epistêmica existente entre as teorias urbanas do Norte global e as teorias urbanas do Sul global (Roy, 2013), onde as primeiras tendem a conceituar as segundas desde sua privilegiada posição epistêmica, e as segundas dormiram na naturalização irreflexiva do discurso ocidental moderno.

O propósito deste artigo é discutir o modelo de análise da teoria urbana contemporânea e o lugar que ocupa o urbano (com seu contraste, a cidade) e o descolonial (com sua antítese, a colonialidade) nela. Inicialmente, trata de explicar como a ideia tradicional de cidade - entendida como categoria analítica (BRENNER; Schmid, 2015; WAchsmuth, 2014) - e a colonialidade do saber - já que gera saberes hegemônicos e marginais (FARRÉs; MATARÁN, 2014; QUIJANO, 2011) - são os fantasmas que recorrem a teoria urbana na atualidade. A partir desta reflexão sobre as perspectivas políticas que ressaltam o direito à cidade e a descolonização 
do saber, conclui destacando o papel crucial que joga na teoria urbana crítica o conceito de cidade e as teorias do Norte global, mas não seus fantasmas.

\section{DISCUSSÃO}

As primeiras reflexões sistemáticas sobre a cidade no século XX concentraram sua análise na maneira como esta constitui um tipo de assentamento diferenciado aos demais. Por exemplo, Park (1999) e diversos representantes da Escola de Chicago definiram a cidade como um ecossistema e um superorganismo no qual era possível encontrar a existência de um fenômeno natural: os grupos sociais se segregavam naturalmente no espaço em um contexto de cooperação competitiva. Para eles, a cidade era diferente a outros assentamentos humanos na medida em que era somente em seus limites onde não apenas se expressava a diferenciação social, senão também a diferenciação funcional de espaços. Assim, a disputa distribuía de maneira hierárquica tanto aos diferentes grupos sociais como aos diferentes usos do solo no seio do ecossistema urbano.

Em todo caso, estes postulados da Escola de Chicago - que representam as tradicionais ideias sobre o urbano no século XX - definiram a cidade como assentamento particular e diferente com respeito aos territórios que se encontravam fora de seus limites geográficos. Isto devido a que o pensamento urbano, desde o surgimento da modernidade, procurou diferenciar analiticamente a cidade de qualquer outro território e formas de vida, sentando precedentes na maneira com a que se observa e define a cidade em função a outro lugar, comumente lugares vazios, selvagens, bárbaros ou rurais (SALCEDO; ZEIDERMAN, 2008). Esta visão estruturou generalizadamente "o inconsciente coletivo dos estudos urbanos do século XX” (WAchsmuth, 2014, p. 24; em livre tradução), o qual não somente definiu a cidade em contraste com a não-cidade, senão que também a assumiu como um cenário autônomo, coerente internamente e comparável a outras cidades-lugares como exemplos de um tipo ideal.

Apesar das distintas batalhas teóricas levadas a cabo por certos representantes da pesquisa urbana deste século (ver, por exemplo, a base epistemológica que construiu WiRTH (2005 [1938]) sobre o urbano), estes esquemas mentais de percepção e divisão foram os que orientaram as principais vertentes teóricas do século XX a realizar diversas análises sobre a cidade e não sobre o urbano. Ou seja, a estabelecer distintas tipologias de assentamentos e não a efetuar análises dos processos socioespaciais. Desta maneira, as correntes de pensamento urbano do século precedente se preocuparam mais em tratar a cidade como um tipo particular 
de espaço limitado de assentamento, antes de entender os processos através dos quais se produz a diferenciação espacial (BRENNER, 2013).

Porém, foi Lefebvre (1970) quem durante a década de setenta começou a questionar esta conceitualização fixa, definitiva e tipológica da cidade. Lefebvre propôs uma epistemologia sobre o urbano, definindo-o como uma formação histórica, um horizonte e uma condição de possibilidade que nasce do processo de implosão-explosão de caráter planetário que alcança a urbanização na sociedade moderna. Em suas próprias palavras, o urbano se define:

Não como realidade consumada, situada no tempo com atraso respeito à realidade atual, senão, pelo contrário, como horizonte e virtualidade classificadora. Se trata do possível, definido por uma direção, ao término do recorrido que chega até ele (LEFEBVRE, 1970, p. 23; grifos colocados, em livre tradução).

Então, para Lefebvre se trata não de aplicar uma ciência da cidade, senão de dar abertura à construção de um conhecimento que permita compreender o processo global pelo qual transcorre o espaço e a sociedade. Desde sua perspectiva, a cidade não podia seguir sendo lida como lugar, senão como processo. Com este argumento revisa uma das suposições que existiam a meados do século XX sobre a oposição entre campo e cidade: estes não são lugares opostos, definidos ou fixos, mas sim são o resultado de lógicas de desenvolvimento desigual e de diferenciação socioespacial. Apesar de que na epistemologia lefebvriana não desapareça a análise sobre a cidade, esta é entendida em correspondência dialética com o urbano. E o urbano é considerado não como um objeto empírico, senão como uma categoria teórica, a qual pode e deve mostrar "uma prática social em movimento" (LeFEBVRE, 1970, p. 23; em livre tradução). Assim, a análise do urbano polemiza a noção de cidade, conceito que, ademais, "parece designar um objeto definido e definitivo" (LeFEBVRE, 1970, p. 23; grifos colocados, em livre tradução).

Estas premissas lefebvrianas se sustentam na ideia de que nada está totalmente acabado, pelo contrário, tudo está em constante mutação: a sociedade como o urbano se refaz continuamente. Este caráter de constante mutação do urbano se separa, então, das noções funcionalistas da cidade que argumentam sua condição de imutabilidade e ordem estabelecido. De modo geral, no campo epistêmico, esta posição examina as análises funcionalistas que se concentram na forma da cidade. Em seu lugar, recomenda o estudo do urbano desde uma corrente de pensamento sustentada em uma visão processual e materialista do espaço social. E é que para Lefebvre tanto a sociedade como o espaço estão localizados em uma lógica dialé- 
tica: o novo nasce através e no seio do anterior. O que impulsa estas perpétuas transformações é a maneira pela qual se estrutura o sistema, ou seja, através das contradições. Por consequência, o urbano, entendido também como abreviatura de sociedade urbana, carrega nas costas a contradição. A qual se concentra em processos urbanos e não em formas urbanas.

Harvey (1996) e representantes da teoria urbana crítica (BRENnER; Schmid, 2016) recuperam e atualizam as contribuições de Lefebvre para referir-se aos processos da urbanização capitalista contemporânea. Particularmente, Harvey outorga importância a reconceitualização do tema urbano na medida em que este não é "uma questão de estudo de algumas entidades quase naturais chamadas cidades, subúrbios, zonas rurais" senão, melhor, é parte fundamental do "estudo dos processos sociais de produção e reprodução espaço-temporal" (HARVEY, 1996, p. 53; em livre tradução).

De igual maneira, a teoria urbana crítica sustenta esta mesma ideia de Harvey. Por um lado, Brenner e Schmid (2016) propõem que o epicentro analítico da teoria urbana deve ser o urbano e os processos de urbanização que estão associados a este termo. Para eles a urbanização contemporânea deve ser entendida como processo e extensão desigual produto da "destruição criativa do espaço político-econômico sob o capitalismo" (BREnNer; Schmid, 2016, p. 66; em livre tradução). Wachsmuth (2014), por sua vez, sugere integrar sistematicamente à teoria urbana uma análise de processos "em lugar da tradicional análise do lugar do cidadeismo metodológico" (WACHSMuth, 2014, p. 33; em livre tradução). Mais precisamente, o cidadeismo metodológico se refere a um enfoque analítico sobre a cidade como lugar. Assim, tal análise tradicional ao que se refere Wachsmuth, usa o conceito de cidade como uma lente analítica e metodológica para compreender os processos de transformação urbana que não ocorrem exclusivamente nos limites internos da cidade, senão que os ultrapassa.

Portanto, estas vertentes teóricas compartilham a construção de um marco epistemológico e a utilização comum de um vocabulário teórico para se referir aos processos que dão conta da urbanização capitalista contemporânea. Priorizam o urbano como processo diante do enfoque analítico da cidade como lugar. Assim, se afastam categoricamente das ideias tradicionais do século XX que consideravam a cidade em oposição ao campo, como um sistema autônomo e como um tipo ideal. Brenner, por exemplo, indica que é tempo de que os teóricos urbanos:

Abandonem a busca de uma essência nominal destinada a distinguir o urbano como um tipo de assentamento (concebido como cidade, cidade-região, mega- 
cidade, metrópoles, megalópoles, etc.) e a concepção similar de outros espaços (suburbanos, rurais, naturais, etc.) como não urbanos devido a sua suposta separação das condições, das tendências e dos efeitos urbanos. Para compreender a produção e a implacável transformação da diferenciação espacial, a teoria urbana deve priorizar a pesquisa de essências constitutivas, ou seja, os processos através dos quais são gerados as heterogêneas paisagens do capitalismo moderno (BRENNER, 2013, p. 56; grifos colocados, em livre tradução).

Porém, esta nova conceitualização ainda se encontra em constante desafio devido a hegemonia do "cidade-centrismo" na teoria urbana. O cidade-centrismo, assim como o cidadeismo metodológico, pode ser entendido como a corrente de pensamento que põe no centro da análise a cidade (entendida como lugar fixo) em vez de colocar o urbano (entendido como processo) como foco de atenção. Apesar deste esclarecimento, diversos estudos, atualmente, seguem definindo seu objeto de pesquisa em contraste com os espaços não urbanos. Seguindo a Wachsmuth, os atuais pesquisadores urbanos continuam se concentrando "em dinâmicas aparentemente endógenas para os espaços urbanos", ao mesmo tempo que persistem em propor "seu objeto de pesquisa em um campo comparativo modular em que todas as cidades são exemplos de um mesmo gênero subjacente apesar da variação" (WACHSMUTH, 2014, p. 25-26; em livre tradução).

E é que para a racionalidade moderna qualquer sistema de conhecimento pode ser desconhecido ou invisibilizado se não corresponde ao esquema prefixado para seu entendimento. $\mathrm{O}$ cidade-centrismo tem estado na mente dos pensadores urbanos há muito tempo, por isso resulta difícil reconhecer as visões que apelam por aproximações processuais do urbano. Neste sentido, alguns autores como Quijano (2011), De Souza Santos (2010) e Grosfoguel (2007) propõem a existência de estruturas e padrões de poder de larga duração que englobam e definem tanto as relações econômicas e políticas, como a cultura, as subjetividades e a produção de conhecimentos. Estes autores também indicam que é possível identificar a hierarquia epistêmica ocidental nos discursos globais da economia, a política e a teoria.

Este último aspecto é o que interessa ressaltar neste artigo já que no campo da teoria urbana é possível perceber a existência de estruturas coloniais de saber através das quais foi exercida a dominação de determinadas correntes de pensamento sobre outras. Pois assim como houve resistência para entender o urbano como processo, também há desistência em reconhecer a essas outras teorias e sistemas de conhecimento que germinam como sistemas de conhecimento úteis para interpretar suas realidades concretas. 
Perspectivas urbanas contra hegemônicas (Robinson, 2006; Roy, 2013; ScHAFRAN, 2014; FARRÉs; MATARÁN, 2014) e perspectivas urbanas latinoamericanas (Pradilla, 2014; VAiner, 2010; SANTos, 1973) situaram esta discussão no plano da modernidade e da colonialidade. Desde estas perspectivas, se entende que a teoria urbana construída no Sul global se encontra em uma posição marginal como produto da colonialidade territorial exercida pelos saberes hegemônicos, mas também se encontra em uma auto encruzilhada como produto do colonialismo intelectual que muitos de seus pensadores reproduzem em suas análises sobre suas cidades. Nos termos de Farrés e Matarán (2014) tal colonialidade se estabelece em:

As próprias práticas profissionais onde certos saberes dominam nas decisões respeito a como conceber e habitar o território, a cidade e a arquitetura. Mostras disto são: o privilégio com que as disciplinas científicas universalizam noções ocidentais de território, cidade e arquitetura; a exportação dos padrões ocidentais de vida urbana; a própria hierarquia outorgada ao "ser urbano" sobre o "ser não-urbano" como modelo de existência; ou a subvalorização que o ensino do desenho urbano-arquitetônico generalizado faz do tradicional, vernáculo ou popular como resposta válida aos problemas atuais (FARrés; MATARÁN, 2014, p. 9; aspas no original, em livre tradução).

Assumindo a modernidade e a colonialidade como variantes a analisar na teoria urbana, Roy (2013) convida a romper a visão euroamericana que a orienta atualmente onde se observa diferentemente as cidades do Norte global em relação às cidades do Sul global, posicionando firmemente a modernidade urbana nas primeiras cidades. Paris, Londres ou Nova York são protótipos de cidades do Norte que definem perfeitamente o moderno. Em troca, as cidades do Sul - que poderia ser qualquer cidade localizada na América Latina, no sul da Ásia, no Oriente Médio ou na África - representam a modernidade atrasada e subdesenvolvida ou, no melhor dos casos, tão somente são vistas como imitadoras da modernidade urbana euroamericana. Neste sentido, Roy propõe questionar fundamentalmente as categorias, conceitos e construções teóricas que observam - desde sua privilegiada posição epistemológica e euroamericana - as realidades de outros contextos e experiências urbanas a partir das suposições de uma modernidade urbana de origem ocidental.

Da mesma maneira, Roy (2013) afirma que um estudo sério desde e sobre as cidades do Sul global pode deslocar o imaginário hegemônico inscrito na teoria urbana contemporânea e, por sua vez, pode revelar o excesso de heterogeneidade e multiplicidade que caracteriza as metrópoles do século XXI. Desde sua visão, a produção 
teórica que se realiza desde as cidades do Sul também poderia contribuir ao conhecimento das cidades do mundo inteiro, sempre e quando o investigador questionar os modelos coloniais e modernistas que estruturam o pensamento urbano. Adotando o marco interpretativo do urbanismo subalterno, afirma que esta posição pode implicar importantes transformações nas condições de como se produz conhecimento das cidades, já que revela a ignorância que envolve os estudos centrados nas cidades do Norte, ao mesmo tempo que aplica uma política de reconhecimento sobre aqueles espaços e saberes do Sul que ficaram à margem da teoria urbana (Roy, 2011, p. 235).

Assim, os estudos sobre o habitat popular na América Latina (MirandA, 2017) ou as descobertas sobre a ação e subjetividade cidadã na África (PıтHouse, 2014) não somente servem para informar sobre a realidade específica de cada região, senão também para argumentar e refletir sobre todas as cidades, sem importar que estas se localizem no Sul ou no Norte global. Estas duas regiões ensinam a diversidade de processos urbanos que exigem de teorias contextualizadas que compreendam melhor a situação habitada do subalterno, em vez deste permanecer invisível ou descuidado como até agora foi feito nos arquivos e anais da teoria urbana do Norte, ou naquela teoria do Sul que replica o colonialismo intelectual.

Especialmente, na América Latina é possível destacar a antecipada e contínua preocupação que tem tido a teoria urbana em fugir do neocolonialismo científico. Milton Santos (1973), por exemplo, identificou como em grande parte da segunda metade do século XX existiu um mimetismo irreflexivo das teorias de desenvolvimento do Norte por parte dos intelectuais latino-americanos. O interesse por renunciar a este colonialismo levou a que o autor desenvolvesse a construção de uma teoria nativa, onde foram levados em conta procedimentos metodológicos mais contextualizados, ao mesmo tempo em que incluía propostas de caráter social e compromissos responsáveis com o próprio entorno. É este legado o que mais se ressalta na revisão das ideias e teorias construídas para explicar os processos urbanos locais e regionais (Delgadillo, 2015). E, por sua vez, é o que tenta manter posturas atuais que desde a geografia crítica (CARLOS, 2012) ou a teoria da planificação (VAINER, 2010) apelam por superar o passado colonial intelectual das teorizações urbanas na região. Em todo caso, os teóricos latino-americanos reivindicam que atualmente necessitam de uma teoria urbana, local e regional:

Que não somente reflita sobre os problemas atuais e herdados, senão uma teoria que nos ajude a construir novas utopias urbanas, que nos guie na construção de cidades e sociedades justas que contribuam para resolver as necessidades da maioria da nossa população (DelgAdiLlo, 2015, p. 270; em livre tradução). 
Neste ponto, podemos observar vários fantasmas na teoria urbana contemporânea que, de maneira similar ao descrito por Rodríguez (2013), mudaram negativamente para perpetrar na visão teórica os vícios associados tanto ao cidade-centrismo como à colonialidade do saber. O primeiro destes se detalha, por exemplo, no procedimento empírico e metodológico que abraçam vários estudos sobre a cidade global ou a ecologia política urbana (WACHSMUTH, 2014) ou na errônea conceitualização dos padrões de urbanização do mundo contemporâneo (BREnner; Schmid, 2016). Igualmente, este primeiro vício é possível encontrar nas propostas teóricas que concentram a atenção em um só lugar para explicar o comportamento dos atores urbanos através do mercado de solo (SCOTT; STORPER, 2013) sem reconhecer a dinâmica profundamente estendida e desigual da urbanização contemporânea.

O segundo vício, por sua parte, se pode evidenciar a partir do intercâmbio internacional desigual de ideias e modelos urbanos (JAJAMOVICH, 2013) que provêm de doutrinas e experiências do Norte, expressadas, por exemplo, nos discursos sobre segurança e inadimplência (DAvis, 2007) ou nas políticas de turismo para áreas urbanas em regeneração (GoNZÁlEz, 2011). O que também se expressa naquelas "boas práticas" muitas vezes celebradas como processos de aprendizagem Sul-Sul, mas que na prática estão fortemente mediadas por organizações inspiradas no Norte (MonTERo, 2017). Da mesma maneira, este vício consegue ser visibilizado mediante a relação hierárquica que exerce a academia, os pensadores e planificadores urbanos sobre quem vive verdadeiramente o urbano (SCHAFRAN, 2014).

Estes fantasmas se materializam, então, em habitus irreflexivos -como seguramente os chamaria Bourdieu - ou, para ser mais concreto, nas "geografias teóricas irreflexivas do cidadeismo metodológico" (WACHSмUTH, 2014, p. 32; em livre tradução), nas teorizações dominantes das cidades-região globais (Roy, 2013) e nos modelos de cidade que atribuem instintivamente a universalidade a uma experiência particular (VAINER, 2010). Visto assim, tanto a ideia tradicional de cidade como a colonialidade do saber representam uma potencial ameaça para o estudo atual do urbano, principalmente se é refletida desde aqueles territórios -como a América Latina - que nunca foram reconhecidos como sujeitos e lugares de enunciação na modernidade.

\section{CONSIDERAÇÕES FINAIS}

De acordo com a discussão anterior, poderíamos sustentar que o principal inimigo a ser erradicado na teoria urbana crítica seria tanto a ideia tradicional de cidade como o saber hegemônico do Norte. Não obstante, aqui sustentamos que 
o conceito de cidade e as teorias do Norte global na teoria urbana contemporânea não devem desaparecer. Estes não tem por que fazê-lo, mas sim seus fantasmas. Se a cidade como conceito não se inclui em uma teoria urbana crítica, como poderíamos nos aproximar das experiências fenomenológicas da urbanização? Como poderia dar-se conta das reivindicações políticas que vários movimentos sociais realizam pelo direito à cidade? Se pretendêssemos eliminar as teorias do Norte do nosso repertório de conhecimento, por acaso não nos transformaríamos naqueles colonizados que - nas palavras de Frantz Fanon- se convertem em perseguidores? Estes questionamentos não pretendem apelar para a construção de uma nova teoria urbana, senão que buscam reivindicar uma atitude crítica que exija um comprometimento da teoria urbana na revisão de suas abordagens sobre o conceito de cidade e das práticas de modernidade e colonialidade que marcam sua prática.

Assim, exercer uma aproximação crítica à teoria urbana teria que reconhecer, por um lado, a cidade como um mapa cognitivo, ou seja, "como uma representação cotidiana dos processos de urbanização" (WACHSMUTH, 2014, p. 32; em livre tradução). Assumir para a teoria urbana esta definição implicaria tratar a cidade como uma categoria da prática, mas não como uma categoría de análise. Desta maneira, é possível dar conta de como se constitui a experiencia cotidiana do espaço urbano e da cidade como uma representação que sucede de tal experiência. Por tanto, a tarefa da pesquisa urbana consistiria em saber em que medida os mapas cognitivos da cidade captam adequadamente ou distorcem os processos de urbanização que representam. Proposta similar apresentam Scott e Storper (2013, p. 22) quando afirmam que o trabalho da teoria urbana consiste em distinguir entre os assuntos que se encontram na cidade - mas que não tem um carácter intrinsicamente urbano- e as questões relacionadas principalmente com o urbano.

E, por outro lado, esta aproximação também deveria aplicar uma atitude e prática descolonial que favoreça a emancipação do pensamento a partir de nascentes e dinâmicas epistemologias, que se concentrem em leituras analíticas localizadas e deslocalizadas (Roy, 2013) em paralelo que estabeleça um pluriversalismo como oposição ao universalismo da tradição ocidental (GROSFOGUEL, 2007). Tal aproximação, então, deve reconhecer essas tantas outras vozes e paradigmas que evadem a racionalidade moderna e que foram esquecidas e silenciadas por uma suposta falta de autoridade enunciativa. Aqui se deve apelar não somente por práticas teóricas que reconheçam em igualdade de condição à teoria produzida tanto no Sul como no Norte globais, senão também pelos sistemas de conhecimento que produzem os habitantes da cidade, quem acumulam experiência e 
saberes (técnicos, simbólicos, etc.) a partir de sua exploração, uso e apropriação do espaço urbano.

Nessa medida, o direito à cidade, ademais de sua ênfase política, alcança um status fenomenológico, que dá conta como distintos sujeitos resistem aos processos de urbanização, ou seja, à destruição criativa capitalista do espaço em escala planetária. A reflexão aqui exposta, ademais, também permitiria ver estas lutas de maneira ampliada sem localismos espaciais e epistemológicos, mas sim como parte de uma revolução urbana ampliada (HARveY, 2013). A qual, por um lado, pensa nas conexões com aqueles setores sociais afins que perseguem objetivos idênticos ao longo dos variados cenários da urbanização estendida e que, por outro, reconheça aqueles sistemas de conhecimentos urbanos que ficaram na marginalidade produto da colonialidade exercida pelos saberes hegemônicos. Assim e somente assim se poderia eliminar da teoria urbana três fantasmas em um só tiro: o fantasma do cidade-centrismo, o fantasma da modernidade e a colonialidade e - quiçá o mais importante de todos - o fantasma da exploração.

\section{REFERÊNCIAS BIBLIOGRÁFICAS}

Brenner, Neil. What is critical urban theory?. City, v. 13, n. 2-3, p. 198-207, 2009.

Tesis sobre la urbanización planetaria. Nueva Sociedad, n. 243, p. 38-66, 2013.

Brenner, Neil; Schmid, Christian. Towards a new epistemology of the urban?. City, v. 19, n. 2-3, p. 151-182, 2015.

La "era urbana" en debate. Eure, v. 42, n. 127, p. 307-339, 2016.

CARlos, Ana Fani Alessandri. Crisis y superación en el ámbito de la Geografía Crítica: construyendo la metageografía. Revista de Geografía Norte Grande, n. 51, p. 5-19, 2012.

DAvis, Diane. El factor Giuliani: delincuencia, la "cero tolerancia" en el trabajo policiaco y la transformación de la esfera pública en el centro de la ciudad de México. Estudios Sociológicos, v. 25, n. 75, p. 639-681, 2007.

Delgadillo, Víctor. Teorías urbanas latinoamericanas: el legado de una gran generación. Economía, Sociedad y Territorio, v. 15, n. 47, p. 261-271, 2015.

De Souza Santos, Boaventura. Descolonizar el saber, reinventar el poder. Montevideo: Ediciones Trilce, 2010.

FARrés, Yasser; Matarán, Alberto. Hacia una teoría urbana transmoderna y decolonial: una introducción. Polis. Revista Latinoamericana, n. 37, p. 1-19, 2014. 
GonzÁLEZ, Sara. Bilbao and Barcelona "in motion". How urban regeneration "models" travel and mutate in the global flows of policy tourism. Urban Studies, v. 48, n. 7, p. 1397-1418, 2011.

Grosfoguel, Ramón. La descolonización de la economía política y los estudios postcoloniales: transmodernidad, pensamiento descolonial y colonialidad global. Tareas, n. 125, p. 53-74, 2007.

Harvey, David. Cities or urbanization?. City, v. 1, n. 1 \& 2, p. 38-61, 1996.

. Ciudades rebeldes. Del derecho a la ciudad a la revolución urbana. Madrid:

Akal, 2013.

JAJAMOvich, Guillermo. Miradas sobre intercambios internacionales y circulación internacional de ideas y modelos urbanos. Andamios, v. 10, n. 22, p. 91-111, 2013.

LEFEBvre, Henri. La revolución urbana. Madrid: Alianza, 1970.

Marx, Karl; EngeLs, Friedrich. El manifiesto del partido comunista. Santiago de Chile: Universitaria, 1971 [1848].

MirANDA, Virginia. El hábitat popular. Algunos aportes teóricos de la realidad habitacional de sectores poseidos. Territorios, n. 36, p. 217-238, 2017

Montero, Sergio. Worlding Bogotá's ciclovía: from urban experiment to international 'best practice'. Latin American Perspectives, v. 44, n. 2, p. 111-131, 2017.

PARK, Robert Era. La ciudad y otros ensayos de ecología urbana. Barcelona: Serbal, 1999. Pithouse, Richard. The shack settlement as a site od politics: reflections from South Africa. Agrarian South: Journal of Political Economy, v. 3, n. 2, p. 179-201, 2014.

Pradilla, Emilio. La ciudad capitalista en el patrón neoliberal de acumulación en América Latina. Cadernos Metrópole, v. 16, n. 31, p. 37-60, 2014.

QUIJANo, Anibal. Colonialidad del podery subjetividad en América Latina. Contextualizaciones latinoamericanas, v. 3, n. 5, p. 1-13, 2011.

Robinson, Jennifer. Ciudades ordinarias. Entrevista a Jennifer Robinson. Población y Sociedad, n. 12-13, p. 207-230, 2006.

Rodríguez, Juan Carlos. De qué hablamos cuando hablamos de marxismo. Madrid: Akal, 2013.

Roy, Ananya. Slumdog cities: rethinking subaltern urbanism. International Journal of Urban and Regional Research, v. 35, n. 2, p. 223-238, 2011.

Las metrópolis del Siglo XXI: nuevas geografías de la teoría. Andamios. Revista de Investigación Social, v. 10, n. 22, p. 149-182, 2013.

Salcedo, Andrés; Zeiderman, Austin. Antropología y ciudad: hacia un análisis crítico e histórico. Antípoda, n. 7, p. 63-97, 2008.

SANTos, Milton. Geografía y economía urbanas en los países subdesarrollados. Barcelona: Oikos-Tau, 1973. 
Schafran, Alex. Debating urban studies in 23 steps. City, v. 18, n. 3, p. 321-330, 2014.

Scott, Allen; Storper, Michael. La naturaleza de las ciudades: el alcance y los límite de la teoría urbana. Espacialidades. Revista de temas contemporáneos sobre lugares, política y cultura, v. 3, n. 2, p. 6-33, 2013.

VAiner, Carlos. "'Hechas de ciudades como nosotros': notas sobre la colonialidad de los modelos de ciudad”. In: Tellier, Luc-Normand; Vainer, Carlos (coods.) Las transformaciones de las metrópolis de las Américas. Bogotá: Universidad Externado de Colombia, 2010, p.383-398.

WACHSMUTh, David. Teoría urbana sin ciudadismo metodológico. Urban, n. 6, p. 23-35, 2014. WiRTh, Louis. Urbanismo como modo de vida. Bifurcaciones, n. 2, p. 7, 2005 [1938]). 